P. C. C. GARNHAM ET $A L$.: HUMAN BABESIOSIS IN IRELAND

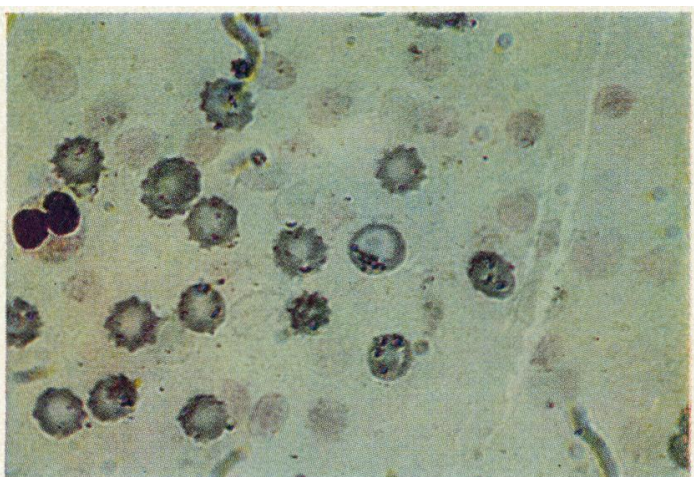

Fig. 1. - B. bovis from fatal infection in man. (x600.)

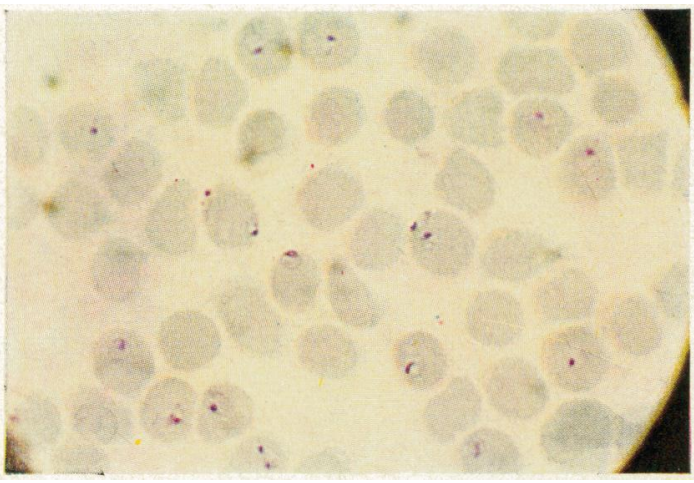

FIG. 2.-P. falciparum : typical infection in man. $(\times 1,000$.

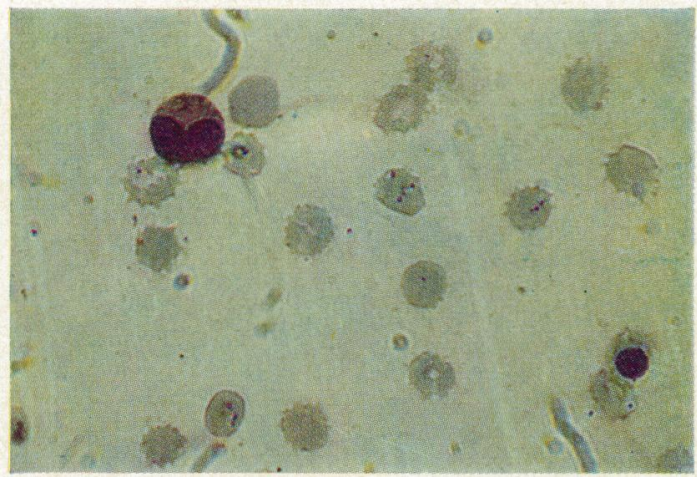

FIG. 3. $-B$. divergens $\underset{(\times 600 .)}{\text { frotal infection in }}$

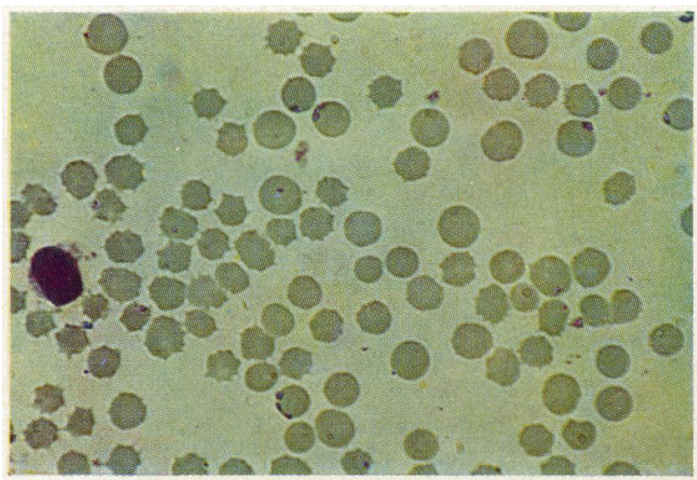

FIG. 4. $-B$. divergens frem cow. $(\times 600$.

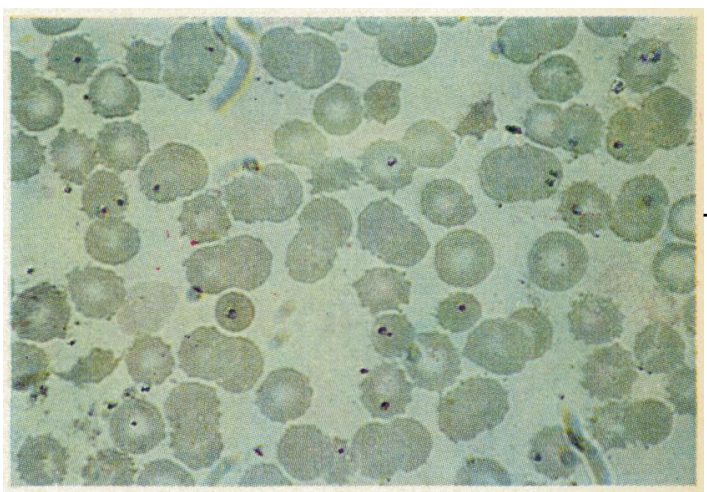

FIG. 5.-B. divergens from chimpanzee. $(\times 600$.

J. E. P. FITZPATRICK ET AL.: THIRD RECORDED CASE OF REDWATER IN MAN
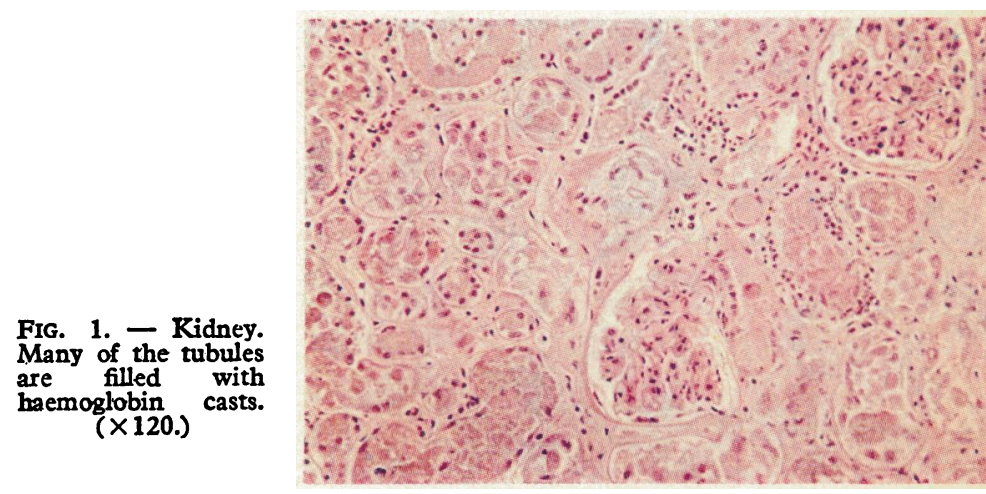

Frg. 2. - Liver. cells in the sinusoids and excess of bile pioment both intracellularly and in bile canaliculi. ( $x$ 200.)

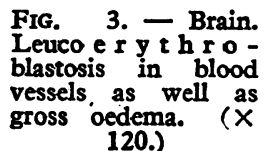

FIG. 3. - Brain. Letico e 1 y 2 hro vessels, as well as gross oedema.

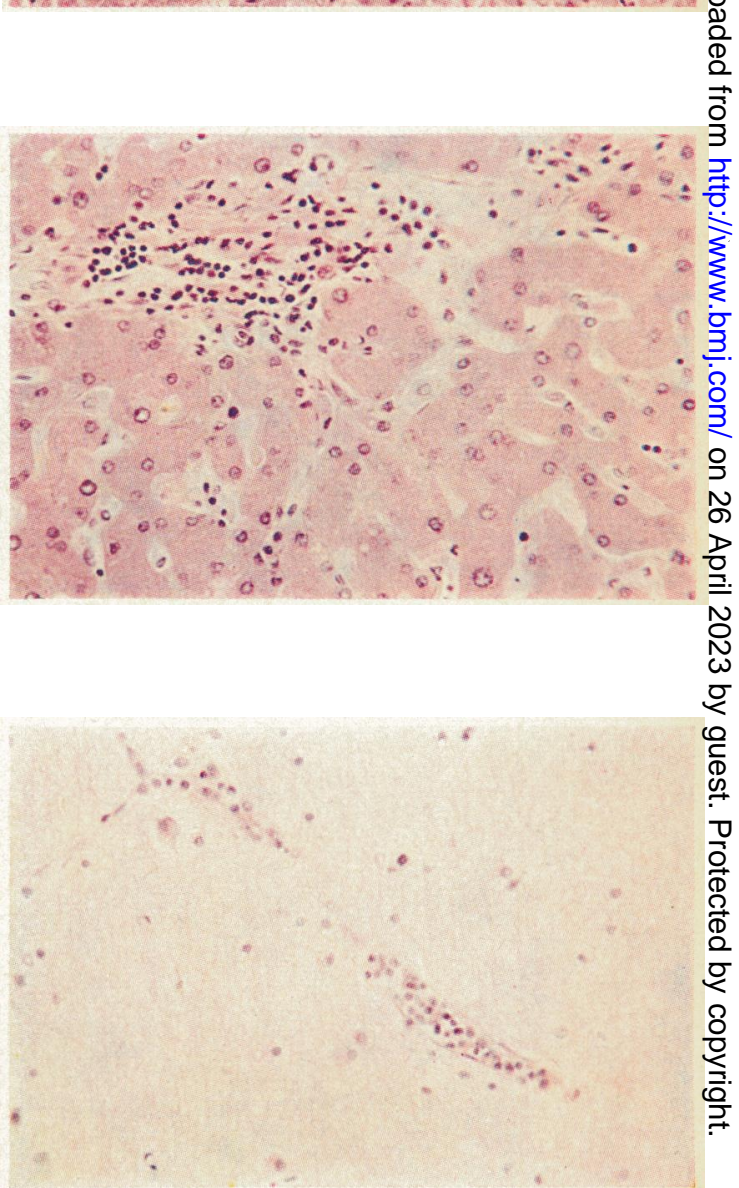


ment of the tick. Cattle allow ticks to complete feeding, but men would tend to remove them as soon as they were noticed. We had no exact data on when the tick-transmitted infection might be expected to appear in human blood. The incubation period in cattle of 8 to 14 days (Joyner et al., 1963) coincides with the period of exposure of the soldiers in the tick-infested fields. The duration of parasitaemia (even if it occurs at all) in unsplenectomized man is unknown, and maximum intensity may occur later than the fortnight period during which these soldiers were exposed. Other factors inhibiting infection in these soldiers may have been present in the environment, such as nutrition, fluoride excess in the water, concomitant infections, etc. Lastly, the experimental techniques may not have been ideal, as the blood was not inoculated until 24 hours after having been taken, though such a delay does not eliminate the infectivity of cattle blood.

Man, particularly agricultural workers and people who spend much time in rural areas, undoubtedly comes into contact with Babesia-infected ticks quite frequently. Three species of piroplasms have been the cause of the three cases reported from human beings. Few places in the world are free of piroplasms ; their presence presents a hazard to numerous people who are splenectomized and an unknown number whose splenic function is deficient.

A follow-up of 1,118 patients who had been splenectomized in England (Lowdon et al., 1966) showed that 417 died in the five years after the operation, and all but six deaths were ascribed to a definite cause. None of the fatalities appeared to have been due to piroplasmosis, but this condition could have been overlooked or misdiagnosed. The great virulence of these infections for man without a spleen and the difficulty of diagnosis make it desirable that the danger should be appreciated. Antimalaria drugs were found to be ineffective in the first human case. A veterinary preparation such as amicarbalide (Diampron) at a dose of $10 \mathrm{mg} . / \mathrm{kg}$. might be considered for use in future cases.
Chimpanzees provide a good experimental model in that these animals suffer from severe infections of $B$. divergens (Colour Plate, Fig. 5) when deprived of their spleens (Garnham and Bray, 1959). The date of spleen removal has no relevance to the intensity of the infection, and it may be assumed that its anti-piroplasmal function cannot be taken over by other tissues. It would be interesting to determine the range of species that can infect chimpanzees and man. Chimpanzees have been shown to be insusceptible to Theileria parva, but at least 30 species of Babesia (sensu latu) remain to be tested.

This work should be extended in suitable enzootic regions, and N.A.M.R.U.-3 is presently undertaking research on similar lines to those described in this paper in the Nile Delta region of Lower Egypt.

We are grateful to our Irish colleagues for their co-operation in this wosk and particularly have to thank Dr. C. F. McConn, regional medical officer, and Mr. J. A. Fagan, veterinary officer, who located the precise site of the infection, and who helped us in many ways. We have much pleasure also in acknowledging the kindness of Drs. Kendall and Joyner, of the Central Veterinary Laboratory, for providing the laboratory facilities for this work and the latter for splenectomizing the calves.

\section{REFERENCES}

Fitzpatrick, J. E. P., Kennedy, C. C., McGeown, M. G., Oreopoulos, D. G., Robertson, J. H., and Soyannwo, M. A. O. (1968). Nature, 217,861 .

Fitzpatrick, J. E. P., et al. (1969). British Medical fournal, 4, 770.

Garnham, P. C. C., and Bray, R. S. (1959). Fournal of Protozoology, 6, 352 .

Joyner, L. P., Davis, S. F. M., and Kendall, S. B. (1963). Experimental

Parasitology, 14, 367.
Lowdon, A. G. R., Stewart, R. H. M., and Walker, W. (1966). British Medical fournal, 1, 446

Nicolle, C. (1961). Destin des Maladies Infectieuses. Geneva, Alliance Culturelle du Livre.

Scholtens, R. G., Braff, E. H., Healy, G. R., and Gleason, N. (1968). American fournal of Tropical Medicine and Hygiene, 17, 810 .

Skrabalo, Z., and Deanovic, Z. (1957). Documenta de Medicina Geographica Tropica, 9, 11 .

\title{
Further Details of Third Recorded Case of Redwater (Babesiosis) in Man
}

\author{
J. E. P. FITZPATRICK,* M.B., M.C.PATH. ; C. COTTON KENNEDY, $\dagger$ D.M., F.C.PATH. \\ MARY G. MCGEOWN, $\ddagger$ M.D., M.R.C.P.ED., PH.D.; D. G. OREOPOULOS, $\S$ M.D. \\ J. H. ROBERTSON, $\|$ M.D., M.R.C.P.ED., M.C.PATH. ; M. A. SOYANNWO,g PH.D., M.R.C.P.I.
}

[With Colour Plate facing Page 768]

\section{British Medical Fournal, 1969, 4, 770-772}

The Fifth Plague, "Behold, the hand of the Lord is upon thy cattle which is in the field, upon the horses, upon the asses, upon the camels, upon the oxen, and upon the sheep: there shall be a very grievous murrain "** (Exodus, chap. 9, v. 3).

Summary : Clinical details and laboratory and post$S$ mortem findings of a human case of redwater (piroplasmosis or babesiosis) caused by Babesia divergens. This is the third proved case in man. All three patients had had splenectomies.

\section{Introduction}

The fulminating haemolytic illness which may result from malarial infection is well known. It is not widely appreciated, however, that a similar illness can be caused in man by infection

\footnotetext{
** "Murrain" in many parts of Ireland is synonymous with redwater in
} cattle, with another intra-erythrocytic protozoon, Piroplasma (Babesia), the cause of redwater disease in animals. There have been only two previous authenticated reports of human piroplasmosis, one from Jugoslavia (Skrabalo and Deanovic, 1957), the other from the United States (Braff and Condit, 1967). The present report is of a third patient who contracted the disease in Ireland. A preliminary account of the case has previously been published (Fitzpatrick et al., 1968).

* Senior Registrar, the Laboratories, Belfast City Hospital, Belfast BT9 7AD.

+ Consultant Clinical Pathologist, the Laboratories, Belfast City Hospital. † Consultant Nephrologist, Belfast City Hospital.

Former Registrar, Department of Nephrology, Belfast City Hospital

Former Registrar, Department of Nephratisy, Belfost City Hospital

Consultant Clinical Pathologist, the Laboratories, Belfast City Hospital of Nephrology, Belfast City Hospital.

Requests for reprints to be sent to Dr. C. C. Kennedy, the Laboratories, Belfast City Hospital, Belfast BT9 7AD, N. Ireland. 


\section{Case Report}

The Irish patient, a 47-year-old fisherman who had never been abroad, became ill on 29 August 1967. He felt poorly, complained of loss of appetite, vomited later, and noticed that he was passing blood in his urine. He was not jaundiced. He had not been taking drugs. Next day he became jaundiced, and on 31 August his doctor sent him into Downe Hospital, Downpatrick, in the care of Dr. C. F. Brennan. The patient was now deeply jaundiced, had a pyrexia of $103^{\circ} \mathrm{F}$. $\left(39.4^{\circ} \mathrm{C}\right.$.), conjunctivitis, and some diarrhoea. He passed urine on 1 September, which is recorded as being "dark" in colour and containing urobilin but not urobilinogen or bile salts. The haemoglobin was $7 \cdot 2$ g. $/ 100 \mathrm{ml}$., the total white cell count was $11,100 / \mathrm{cu}$. mm, with a polymorphonuclear leucocytosis. The blood was reported as grossly haemolysed in the specimen bottle.

A specimen of blood taken for estimation of urea and electrolytes on 2 September was found to be completely laked, and a second sample taken the same day, also haemolysed, was reported as follows: urea $273 \mathrm{mg} . / 100 \mathrm{ml} ., \mathrm{CO}_{2}$ total 12 , sodium 122 , potassium 5.0 , chloride 100 , and protein $14.9 \mathrm{mEq} /$ litre respectively The total bilirubin was $5.4 \mathrm{mg} . / 100 \mathrm{ml}$. (dinect $1 \cdot 1$ ), thymol turbidity 2 units, alkaline phosphatase 5 K.A. units, and transaminase 820 units. The clinical diagnosis at this stage was Weil's disease.

On 2 September the patient, now anuric, was transferred to the renal unit, Belfast City Hospital, On arrival he was moribund, disoriented, and unable to give a history. The jaundice was a greenish bronze colour. His temperature was $99 \cdot 8^{\circ} \mathrm{F}$. $\left(37 \cdot 7^{\circ} \mathrm{C}\right.$.) Conjunctivitis was no longer obvious, but there were numerous petechiae over the lower limbs. The blood pressure was $80 / 50$ $\mathrm{mm}$. Hg. There was tenderness and guarding over the liver, which was enlarged $2 \frac{1}{2}$ in. $(6 \cdot 3 \mathrm{~cm}$.) below the costal margin. The spleen was not palpable and there was a fairly recent left paramedian upper abdominal scar, with a 4-in. $(10-\mathrm{cm}$.) transverse extension to the left.

He was treated with massive doses of penicillin (the results of the Weil's agglutination test not then being known), hydrocortisone, and peritoneal dialysis. Despite this treatment he continued to deteriorate, and by the morning of 4 September the blood urea had risen to $312 \mathrm{mg} . / 100 \mathrm{ml}$., and the serum amylase was 565 Somogyi units. The agglutination test against Leptospira icterohaemorrhagiae and $L$. canicola was negative. It was known that the patient had had blood transfusions some months before, and the possibility of serum hepatitis, already considered, now seemed more probable. On the following day the haemoglobin was $4.0 \mathrm{~g} . / 100 \mathrm{ml}$., haematocrit $12 \%$, and the total white cell count $46,500 / \mathrm{cu}$. mm. The red cells numbered $1.0 \times 10^{\%} / \mathrm{cu}$. mm., the mean corpuscular haemoglobin concentration was $32 \%$, mean corpuscular volume $120 \mathrm{cu}$. $\mu$, and the reticulocytes $25 \%$. The differential count showed polymorphonuclears $47 \%$, metamyelocytes $19 \%$, myelocytes $22 \%$, lymphocytes $12 \%$, and there were 36 primitive red oells per 100 leucocytes, some megaloblastic in appearance. The red cells were macrocytic, with anisocytosis, polychromasia, and many distorted and fragmented forms. A striking feature was the presence of numerous intra-erythrocytic inclusions. The direct antiglobulin (Coombs) test was negative and no Heinz bodies were seen in supravital preparations.

The patient died before this detailed blood repont and further laboratory findings described later became available. He had continued to deteriorate despite intensive treatment, and an exchange transfusion was in preparation when death occurred on 5 September.

The laboratory diagnosis at this stage was blackwater fever following a malignant tertian (Plasmodium falciparum) infection, probably transmitted by a blood transfusion. The intra-erythrocytic inclusions seen in the blood film often numbered more than one, and occasionally up to eight, in each infested red blood cell. Their morphology was most unusual; shapes varied from a single large chromatin dot to rings, loops, clubs, thin or thick rods, piriform varieties, indefinite amoeboid patterns, and occasional divergent forms. No intra-erythrocytic inclusions were at the time seen in the blood films of 1 September, but after they were found in the films of 5 September retrospective examination revealed that they had been present on the first occasion.

\section{Further Investigations}

Further inquiries showed that the patient had had an operation at the West Cumberland Hospital, Whitehaven, on 12 May 1967, following a severe haematemesis after perforation of a duodenal uloer. A posterior gastroenterostomy and vagotomy were performed, and because of technical difficulties the spleen was torn and had to be removed.

For some weeks it was assumed that the patient's death in September was due to malaria contracted from a blood transfusion given at this previous operation. In the British Isles only five cases of malaria transmitted by a blood transfusion have been reported (Thomas, Keys, and Dyke, 1936 ; Nabarro and Edward, 1939 Rogers, 1947 ; Grant, Perinpanayagam, Shute, and Zeitlin, 1960 ; Vartan, 1967), and attempts were made at once through colleagues in England to trace a malaria carrier among the donors whose blood was given at the operation. Meanwhile visits were made to the patient's home in a seaside town in Northern Ireland and his wife was able to give a detailed history. The remote possibility of picking up a malarial infection there or during the caravan holiday in County Galway in mid-August was explored, but the acquisition of $P$. falciparum malaria in Ireland is well-nigh impossible, though a case of benign tertian malaria was reported in a member of the W.R.N.S. in County Derry by Birrel (1946).

At this time there began to be a doubt about the correctness of the diagnosis because malarial pigment was not found in the organs at necropsy and it was about 15 weeks since the patient had received a blood transfusion, a most unlikely incubation period for the transmission of malaria. Also examination of the blood donors had failed to reveal a malaria carrier. It was then reported by the Malaria Reference Laboratory, Epsom, Surrey, that the infection was, in fact, babesiosis (piroplasmosis) and the species Babesio divergens.

\section{Post-mortem Findings}

The external findings were as described above. All the body cavities contained an excess of bile-stained fluid. The heart was normal. The lungs were heavy with oedema fluid. The liver, which weighed 2,100 g., was smooth and uniformly yellow. The spleen was absent, The stomach showed a patent gastroenterostomy and there was some scarring of the duodenum. The pancreas was swollen and oedematous, showing focal areas of fat necrosis. The kidneys were uniformly enlarged and each weighed $225 \mathrm{~g}$. ; they were intensely congested, with the cortico-medullary junction picked out by dark red-brown pigment. The pelves were normal. The urinary bladder contained $30 \mathrm{ml}$. of almost black urine. The brain was swollen and the meninges were tinged with bile. There were no petechial haemorrhages or areas of infarction. The adrenals were swollen and friable, but the thyroid, parathyroid, and pituitary were macroscopically normal.

\section{Histology}

In all organs the vessels contained many normoblasts and immatune white cells. The kidneys showed a profound haemoglobinuric nephrosis (Colour Plate, Fig, 1). Many tubules were filled with dark brown haemoglobin casts. Others showed varying degrees of cloudy swelling. The glomeruli, apart from a slight swelling of the outer layer of Bowman's capsule, were normal. The liver sinusoids contained an excess of nucleated cells (Colour Plate, Fig. 2) but the Kupffer cells, though in places swollen, contained no "malarial pigment." Bile pigment was present in excess within both the liver cells and the interlobular bile canaliculi. The Prussian blue neaction was negative.

Within the cerebral vessels the leucoerythroblastosis was especially prominent (Colour Plate, Fig. 3). Though most vessels were distended with cells there was no focal " plugging." There was much perivascular fixation shrinkage indicative of gross oedema, but nowhere were perivascular ring haemorrhages or areas of necrosis found.

No malarial pigment or excess haemosiderin was present in the bone marrow. The adrenals showed vacuolation and degeneration of the zona fasciculata.

\section{Discussion}

Piroplasmosis (babesiosis) is a world-wide tick-borne disease of many wild and domestic animals. The protozoon was first described by Babes (1888), who gave his name to the genus. 
The parasites are non-pigmented, inhabit the red blood cells, and may be mistaken for malaria in humans. The disease is familiar to farmers as " redwater" in cattle. Only three human cases have been authenticated, and all, before being infected, had had splenectomies.

Unlike the two previaus human cases of babesiosis the Irish patient rarely walked through fields, and no cases of redwater had been reported for years in the neighbourhood of his home. The evidence points to his having acquired the infection in County Galway in mid-August, while on a short caravan holiday. Further weight is added to this belief because three cases of redwater in cattle were reported from that area in that month (MacCon, 1967). A field study beside the caravan was undertaken at a later date (Garnham, Donnelly, Hoogstraal, Kennedy, and Walton, 1969).

In contrasting the haemoglobinuria of babesiosis in cattle with blackwater in humans, Thomson (1924) wrote that the former is always associated with numerous parasites in the peripheral blood, whereas malaria parasites are usually not numerous at the onset of blackwater. Maegraith (1946) stated that malaria parasites are found in the peripheral blood in about half the active cases of blackwater fever. There is a parallel to the redwater of cattle in the blood findings of the human case now reported: Shute (1967), commenting on the latter, pointed out that maximum parasitaemia seems to occur when redwater is at its height. Skrabalo and Deanovic (1957) thought that piroplasmosis should be added to the list of causes of acute haemolytic anaemia in man.

The American patient, who had had a splenectomy for hereditary spherocytosis, was initially regarded as a case of malaria and treated with chloroquine. Perhaps other patients in the past-with or without a spleen-have also been misdiagnosed as malaria, treated as such, and recovered.

We are indebted to Professor P. C. C. Garnham and Mr. P. G. Shute, Malaria Reference Laboratory, Horton Hospital, Epsom,
Surrey, for identifying the parasite. We are grateful for the helpful co-operation afforded by Dr. T. T. Baird, Deputy Chief Medical Officer, Ministry of Health and Social Services, Northern Ireland. We acknowledge the help of Dr. Sheila Murray, Director of the Blood Transfusion Service, Newcastle upon Tyne. We thank Mr. E. H. Crozier for the photomicrographs.

ADDENDUM.-A further case of human babesiosis has recently been reported (Benson, Galdi, Altman, and Fiurmara, 1969). The patient, a 59-year-old woman, who was treated with chloroquine, recovered. This is the first account of babesiosis in a human being with an intact spleen. The parasite is stated possibly to be Babesia rodhaini, a rodent species.

\section{REFERENCES}

Babes, V. (1888). Comptes Rendus Hebdomadaires des Séances de l'Académic des Sciences, 107, 692.

B. (1969) Morbidity and Mortality Weekly Reports, 18, 277.

Birrell, N. V. (1946). British Medical foumal, 1, 649.

Braff, E., and Condit, P. (1967). Morbidity and Mortality Weekly Reports, 16, 8.

Fitzpatrick, J. E. P., et al. (1968). Nature, 217, 861.

Garnham, P. C. C., Donnelly, J., Hoogstraal, H., Kennedy, C. C., and Walton, G. A. (1969). British Medical fournal, 4, 768.

Grant, D. B., Perinpanayagam, M. S., Shute, P. G., and Zeitlin, R. A. (1960). Lancet, 2, 469.

MaoCon, C. F. (1967). Personal communication. County Medical Officer, Galway, Republic of Ireland.

Maegraith, B. G. (1946). Tropical Diseases Bulletin, 43, 801.

Nabarro, D., and Edward, D. G. ff. (1939). Lancet, 2, 556.

Rogers, K. B. (1947). Lancet, 2, 688.

Shute, P. G. (1967). Personal communication. Assistant Director, Malaria Reference Laboratory, Epsom, Surrey.

Skrabalo, Z, and Deanovic, Z. (1957). Documenta de Medicina Geographica et Tropica, 9, 11.

Thomas, W. L., Keys, S., and Dyke, S. C. (1936). Lancet, 1, 536.

Thomson, J. G. (1924). Researches on Blackwater Fever in Southerm Rhodesia. London School of Tropical Medicine. Research Memoir Series, Vol. VI.

Vartan, A. E. (1967). British Medical fournal, 4, 466.

\title{
Results of Treatment of Dermatitis Herpetiformis with a Gluten-free Diet after One Year
}

\author{
R. MARKS,* M.B., B.SC., M.R.C.P., D.T.M.\&H. ; M. W. WHITTLE, $†$ M.B., B.SC.
}

Summary : Twenty-one patients with dermatitis herpetiformis initially controlled by dapsone or sulphonamides have been treated with a gluten-free diet and reassessed at intervals for up to 15 months (mean 11.9 months). According to routine histological and dissecting microscope criteria the small-bowel lesion improved in 10, but when mean epithelial cell height was used as a measure 15 patients improved. Five of the patients with diarrhoea improved after withdrawing gluten from the diet but none reverted to completely normal bowel habit. The tests for malabsorption showed little improvement in the treatment period. Twelve patients needed less dapsone to control their skin complaint, the mean dose falling from $144 \mathrm{mg}$. to a mean of $70 \mathrm{mg}$. per day; of these three stopped using this drug altogether.

- Senior Registrar and Tutor, St. John's Hospital for Diseases of the Skin, London W.C.2.

\section{Introduction}

The association of disease of the small intestine with dermatitis herpetiformis is now well documented (Marks, Shuster, and Watson, 1966 ; Van Tongeren, Van der Staak, and Schillings, 1967 ; Fry, Keir, McMinn, Cowan, and Hoffbrand, 1967 ; Fraser, Murray, and Alexander, 1967; Marks, Whittle, Beard, Robertson, and Gold, 1968 ; Bendl and Williams, 1968). The similarities of the jejunal disorder to the coeliac syndrome have raised the question of the effectiveness of a gluten-free diet in dermatitis herpetiformis. There are two ways in which such treatment may be beneficial ; the small-bowel disorder could be improved, the skin disease remit, and the need for dapsone be eliminated. Fry, McMinn, Cowan, and Hoffbrand (1968) described the treatment of seven patients and Shuster, Watson, and Marks (1968) the treatment of five patients with gluten-

† Research Assistant, Department of Surgery, St. George's Hospital, London S.W.1. 